\title{
PLANTAS DE COBERTURA SOBRE ATRIBUTOS AGRONÔMICOS DO MILHO NA REGIÃO SUDOESTE DA AMAZÔNIA
}

\author{
ANDRÉIA MARCILANE AKER ${ }^{1}$, ALEXANDRE MARTINS ABDÃO DOS PASSOS², \\ ALAERTO LUIZ MARCOLAN ${ }^{3}$, FLÁVIA CRISTINA DOS SANTOS ${ }^{2}$, \\ HENRIQUE NERY CIPRIANI ${ }^{3}$ e LIDIANE APARECIDA DE VARGAS ${ }^{1}$
}

\author{
'Universidade Federal de Rondônia, andreiaaker@hotmail.com, lidianeavargas@gmail.com \\ ${ }^{2}$ Embrapa Milho e Sorgo,alexandre.abdao@embrapa.br, flavia.santos@embrapa.br \\ ${ }^{3}$ Embrapa Rondônia, alaerto.marcolan@embrapa.br, henrique.cipriani@embrapa.br
}

Revista Brasileira de Milho e Sorgo, v.15, n.3, p. 531-542, 2016

\begin{abstract}
RESUMO - O sistema plantio direto é uma estratégia sustentável de produção que preconiza a manutenção da cobertura vegetal como prática conservacionista do solo. Objetivou-se avaliar o efeito de plantas de cobertura sobre atributos fisiológicos e agronômicos do milho na região sudoeste da Amazônia. Foram avaliadas 15 estratégias de sucessões de culturas com o milho e a influência sobre o rendimento de biomassa, de grãos, altura de plantas e inserção da espiga, índice de espiga, massa de 100 grãos, teor foliar de nitrogênio e clorofilas total, a e b em plantas de milho. Observou-se efeito das plantas de cobertura sobre o rendimento de grãos, de biomassa fresca e seca, na massa de grãos e nos teores de clorofila. Os efeitos sobre os teores de clorofila foram mais pronunciados na clorofila b e nos estádios fenológicos finais da cultura. O feijão-de-porco promoveu as maiores produtividades de grãos $\left(7.539,3 \mathrm{~kg} \mathrm{ha}^{-1}\right) \mathrm{e}$ potencial de silagem (16,2 $\mathrm{Mg} \mathrm{ha}^{-1}$ de biomassa seca). A adequada escolha das espécies que compõe um sistema de plantio direto é preponderante para o apropriado desempenho agronômico do milho na região sudoeste da Amazônia.

Palavras-chave: Zea mays, intensificação ecológica, sustentabilidade, integração lavoura-pecuária, plantio direto.
\end{abstract}

\section{CROPPING SYSTEMS ON THE PERFORMANCE OF CORN PLANTS IN THE SOUTHWESTERN AMAZON}

\begin{abstract}
A sustainable strategy for agricultural systems is the use of cover crops in no-tillage systems, as a conservationist soil practice. This paper aimed to evaluate the short-term effects of different cover crops on some physiological and agronomic attributes of corn crop in the Southwestern Amazon region. The effects of 15 cover plants on the biomass and grains yield, plant height, ear insertion height, ear index, mass of 100 grains, leaf nitrogen content and $\mathrm{a}, \mathrm{b}$ and total chlorophyll levels of corn plants were evaluated. A randomized complete block design was used with four replications. Grain yield, fresh and dry biomass yield, mass of 100 grains and chlorophyll content were affected by some cover crops. Jack bean promoted the highest grain yield (7,539.3 $\left.\mathrm{kg} \mathrm{ha}^{-1}\right)$ and biomass yield (16.2 $\mathrm{Mg} \mathrm{ha}^{-1} \mathrm{dry}$ matter) among the options assessed. Cover crops provided different levels of total, a and $\mathrm{b}$ chlorophyll levels, on the corn plants. Some cover crops presented the potential to improve the agronomic performance of the succeeding corn crop in the Southwestern Amazon region. The proper agronomic performance of corn in a no-till system depends on the adequate choice of cover plants to compose the system.
\end{abstract}

Keywords: Zea mays, ecological intensification, sustainability, crop-livestock system, no-till. 
A cultura do milho possui destaque nos agronegócios mundial e brasileiro, por apresentar-se como matéria-prima impulsionadora de diversos complexos agroindustriais voltados tanto para a nutrição humana, quanto para a alimentação animal. Em Rondônia, é uma das principais culturas em área plantada, utilizada em propriedades desde o cultivo de subsistência até níveis elevados de tecnologias (Godinho, 2008). Contudo, a produtividade ainda é insatisfatória devido à baixa fertilidade natural dos solos e à baixa capacidade de investimento por parte dos produtores rurais (Schlindwein et al., 2014).

Visando ao aumento da produtividade e à manutenção do equilíbrio do sistema, o uso de plantas de cobertura revela-se uma alternativa para a região (Maia et al., 2013). A inserção de plantas de cobertura atua na promoção da ciclagem de nutrientes no agroecossistema (Boer et al., 2007), tornando-os mais disponíveis para as culturas agrícolas (Ziech et al., 2015). Na região Amazônica, os processos de mineralização e de perda da matéria orgânica ocorrem de forma intensa, devido às elevadas temperaturas associadas a altos índices pluviométricos (Cerri et al., 2007). No entanto, pesquisas com a utilização de plantas de cobertura na região Amazônica são escassas e necessárias para a viabilização do sistema plantio direto na região.

Considerando o perfil distrófico predominante nos solos da região, a utilização de plantas de cobertura apresenta como benefício a redução do uso de fertilizantes (Rosa et al., 2011), especialmente os adubos nitrogenados, que possuem alto custo e podem ser substituídos, em parte, pelo uso de plantas leguminosas fixadoras de nitrogênio atmosférico (A1buquerque et al., 2013). Neste quesito, a utilização de plantas de cobertura pode significar uma forma de agricultura de baixa emissão de gases de efeito estufa, contribuindo para mitigar efeitos das mudanças climáticas e promovendo aumento da sustentabilidade dos agroecossistemas (Basches et al., 2014; Mukherjee \& Lal, 2015).

Na cultura do milho, a utilização de plantas de cobertura tem se mostrado uma estratégia efetiva para promover não só o melhor condicionamento do solo, como o aumento da produtividade de grãos (Albuquerque et al., 2013; Carvalho et al., 2015). O efeito sobre a produtividade pode advir, além do maior aporte de nutrientes às plantas, de efeitos benéficos das plantas de cobertura sobre a fisiologia do milho, especialmente em anos de condições climáticas atípicas (Mahama et al., 2016).

Neste sentido, o objetivo deste trabalho foi verificar os efeitos de plantas de cobertura sobre a cultura do milho em sistema de plantio direto na região Sudoeste da Amazônia.

\section{Material e Métodos}

O estudo foi desenvolvido no campo experimental da Embrapa Rondônia, no município de Porto Velho, RO, localizado na latitude de $8^{\circ} 47^{\prime} 53,00^{\prime \prime} \mathrm{S}$, na longitude $63^{\circ} 51^{\prime} 02,82^{\prime \prime} \mathrm{O}$ e na altitude de $87 \mathrm{~m}$. O experimento foi conduzido na safra 2014/2015, com a semeadura das plantas de cobertura realizada na entressafra de 2014 e o milho em sucessão, na safra principal. A área experimental foi conduzida sob plantio direto desde 2008, com a cultura de soja na safra e pousio na entressafra. O solo é classificado como Latossolo Vermelho-Amarelo distrófico. Previamente à implantação das plantas de cobertura, foram realizadas a amostragem e a análise de solo para caracterização dos atributos químicos (Tabela 1). 
Tabela 1. Atributos químicos do solo na profundidade de 0 a $20 \mathrm{~cm}$. Porto Velho, Rondônia, 2014.

\begin{tabular}{|c|c|c|c|c|c|c|c|c|c|c|}
\hline pH & MO & $\mathbf{P}$ & $\mathbf{K}$ & $\mathbf{C a}^{2^{+}}$ & $\mathrm{Mg}^{2+}$ & $\mathbf{H}+\mathbf{A l}$ & $\mathbf{A l}^{3+}$ & CTC & m & $\mathbf{V}$ \\
\hline $\mathrm{H}_{2} \mathrm{O}$ & $\mathrm{g} \mathrm{kg}^{-1}$ & $\mathrm{mg} \mathrm{dm}^{-3}$ & & \multicolumn{5}{|c|}{ - $\mathrm{cmol}_{\mathrm{c}} \mathrm{dm}^{-3}$} & \multicolumn{2}{|c|}{$\%$} \\
\hline 5,05 & 38,36 & 7,13 & 0,20 & 2,67 & 1,96 & 10,77 & 1,59 & 15,61 & 27,81 & 30,25 \\
\hline
\end{tabular}

pH em água 1:2,5; M.O. por digestão úmida; P e K determinados pelo método Mehlich1; Ca, Mg e Al trocáveis extraídos KCl 1 mol $\mathrm{L}^{-1}$. CTC: capacidade de troca de cátions. m: saturação por alumínio. V: saturação por bases.

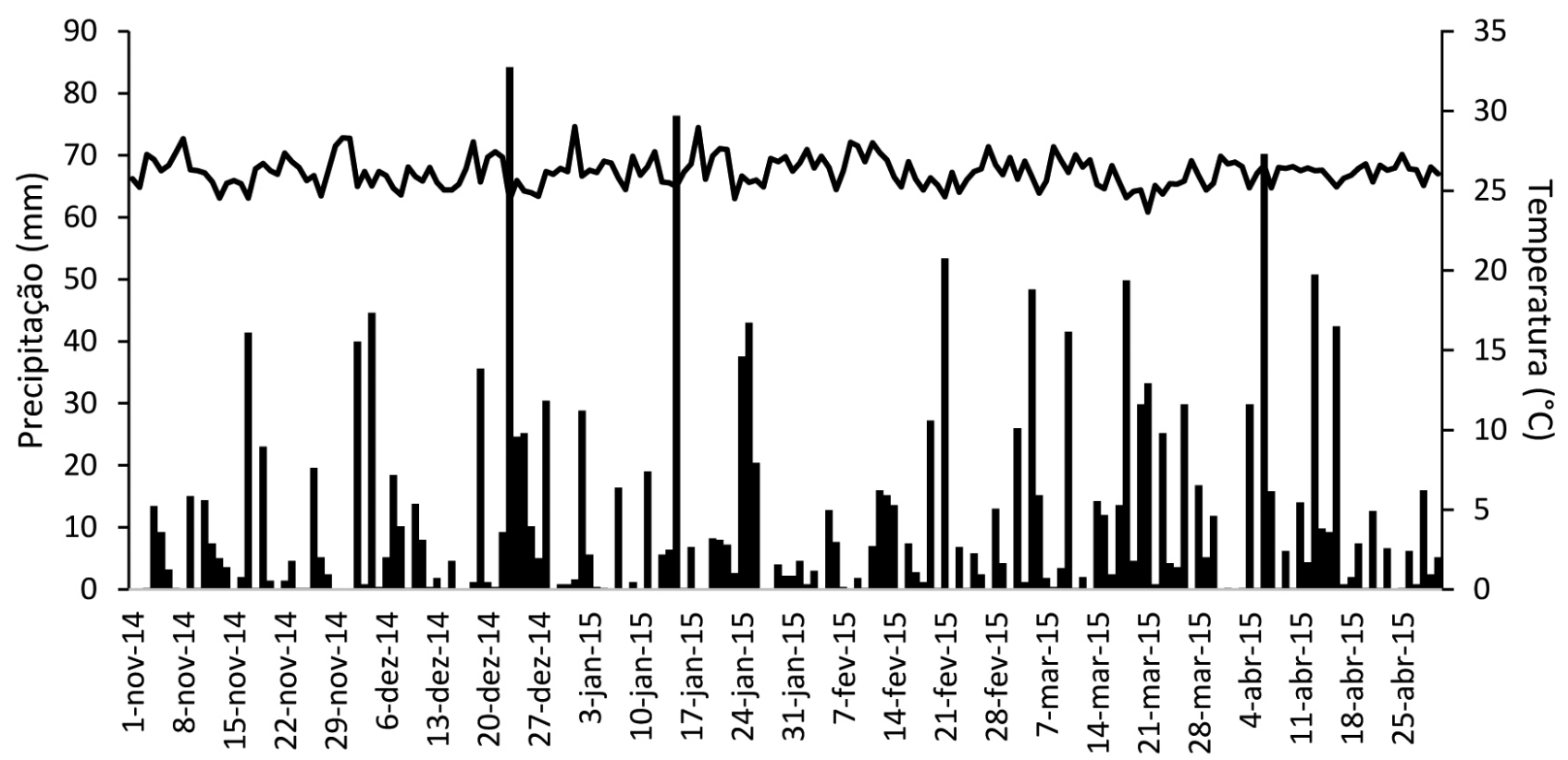

Figura 1. Precipitação pluviométrica (barras) e temperatura diária média (linha) no período de novembro de 2014 a abril de 2015 em Porto Velho, RO. Fonte: Estações meteorológicas do Instituto Nacional de Meteorologia e da Secretaria de Estado de Desenvolvimento Ambiental lotadas na Embrapa Rondônia.

De acordo com a classificação de Köppen, o clima regional é classificado como Am, tropical de monções, com temperatura média anual de $25,6^{\circ} \mathrm{C}$. A precipitação média anual é de $2.200 \mathrm{~mm}$, apresentando uma estação chuvosa de outubro a maio e estação seca de junho a setembro, com evapotranspiração potencial média anual de $1.455 \mathrm{~mm}$ (Cunha \& Schöffel, 2011). Os dados climatológicos no período são apresentados na Figura 1.

Os tratamentos foram compostos por 14 plantas de cobertura em sucessão à soja na safra 2013/2014: Urochloa brizanta "Piatã", Urochloa brizanta "Xaraés", Urochloa ruziziensis, capim -sudão (Sorghum sudanense "BRS Estribo"), milheto (Pennisetum glaucum "BRS 1501"), milho (Zea mays "BR 106"), Crotalaria juncea, sorgo (Sorghum bicolor "BRS 310"), Crotalaria ochroleuca, Crotalaria spectabilis, feijão-guandu ( $\mathrm{Ca}$ janus cajan), feijão-de-porco (Canavalia ensiformis), mucuna-cinza (Mucuna cinereum) e mucunapreta (Mucuna aterrima), e pousio, totalizando 15 tratamentos.

A cultura do milho foi semeada com espaçamento entrelinhas de $0,9 \mathrm{~m}$; as leguminosas e o sorgo 
com $0,45 \mathrm{~m}$ e as demais com $0,225 \mathrm{~m}$. Não foram realizadas inoculação das sementes das leguminosas e adubação de plantio em nenhuma planta de cobertura. $\mathrm{O}$ delineamento experimental adotado foi o de blocos completamente casualizados, com quatro repetições. As parcelas consistiram de cinco linhas de $10 \mathrm{~m}$ de comprimento, compreendendo a área útil duas linhas centrais de $8 \mathrm{~m}$ lineares de onde excluíram-se $1 \mathrm{~m}$ de cada extremidade a título de bordadura.

O corte das plantas de cobertura foi realizado com auxílio de uma roçadora costal. As épocas de corte ocorreram na maturação de grãos para o milho, o milheto, o sorgo e o capim-sudão; em pleno florescimento para as leguminosas; e aos 55, aos 108 e aos 172 dias após semeadura para as braquiárias, simulando o pastejo por gado em um sistema de integração lavoura-pecuária, com cortes a $30 \mathrm{~cm}$ de altura do solo. O material ceifado das braquiárias foi removido da área, simulando a exportação do material via consumo dos animais. A Crotalaria juncea e a $C$. spectabilis já apresentavam início de frutificação no momento do corte. Todas as parcelas foram dessecadas previamente à semeadura da safra 2014/2015, utilizando-se mistura de $1.440 \mathrm{~g} \mathrm{ha}^{-1} \mathrm{de}$ glifosato $+25 \mathrm{~g} \mathrm{ha}^{-1}$ de flumioxazina $+0,5 \%$ de óleo mineral.

Sobre as palhadas das plantas de cobertura semeadas em abril de 2014, foi realizada a semeadura do milho no dia 03/12/2014, utilizando-se o híbrido simples RB 9308 YG VTPRO, por meio de semeadora adubadora, com espaçamento de $0,90 \mathrm{~m}$ e uma população final de plantas de 70.000 plantas ha $^{-1}$. Para a adubação de semeadura, foi utilizada a fórmula NPK 05-25-20 na dose de $400 \mathrm{~kg} \mathrm{ha}^{-1}$. $\mathrm{Na}$ adubação de cobertura, foram usados $140 \mathrm{~kg}$ ha $^{-1}$ de nitrogênio, nos estádios fenológicos V4 (70 $\mathrm{kg} \mathrm{ha}^{-1}$ na forma de sulfato de amônio) e V8 (70 $\mathrm{kg} \mathrm{ha}^{-1}$ na forma de ureia), aplicados manualmente em filetes ao lado das plantas. Todos os demais tratos culturais foram realizados conforme preconizado para a cultura (Godinho, 2008), não havendo necessidade de controle de insetos-praga e plantas daninhas na área.

Na maturidade fisiológica da cultura do milho, foi avaliada, por meio da colheita de duas linhas de 5 $\mathrm{m}$ da área útil, a produtividade de grãos $\left(\mathrm{kg} \mathrm{ha}^{-1}, \mathrm{com}\right.$ umidade ajustada para $13 \%$ ) e, concomitantemente, mensurados os seguintes atributos agronômicos em dez plantas tomadas ao acaso na área útil: altura de planta, altura de inserção da espiga, número de plantas acamadas, população final de plantas, índice de espiga (número de espigas por planta) e massa de 100 grãos.

Nos estádios reprodutivos, foram realizadas leituras indiretas do teor de clorofila foliar (índice CLOROFILOG), por meio de um medidor indireto de teor de clorofila (FALKER, modelo CFL1030), nos estádios fenológicos de pendoamento, de florescimento feminino, de grão leitoso, de grão pastoso, de grão farináceo e na maturação (maturidade fisiológica). As leituras foram realizadas no terço médio da folha-índice (primeira oposta e abaixo da espiga), em dois pontos da folha, na parte central e a $2 \mathrm{~cm}$ da borda foliar, avaliando-se 10 plantas por parcela (Mahama et al., 2016).

No florescimento feminino, foram coletadas folhas para análise foliar dos teores de nitrogênio na planta. As amostras foliares foram secas em estufa de circulação forçada de ar, a $65^{\circ} \mathrm{C}$, até atingirem massa constante. Em seguida, foram trituradas em moinho tipo Willey e analisadas de acordo com o método Kjeldahl.

No estágio de desenvolvimento farináceo a farináceo duro (dois terços da linha do leite), fo- 
ram coletadas plantas de milho em uma linha de $8 \mathrm{~m}$ para a avaliação das biomassas fresca e seca para estimativa do potencial de silagem (Souza Sobrinho et al., 2004). O corte foi realizado manualmente a uma altura de $15 \mathrm{~cm}$ do solo. A biomassa da matéria fresca foi mensurada e, após secagem das mesmas em estufa de ventilação forçada sob $65^{\circ} \mathrm{C}$ por $72 \mathrm{~h}$, foi aferida a matéria seca e foi estimado o rendimento de biomassa (Souza Sobrinho et al., 2004). Em cinco plantas secas tomadas ao acaso, realizou-se a avaliação dos componentes estruturais, fracionando as plantas em colmos (C), folhas $(F)$ e espigas (E), que foram posteriormente pesadas, visando a determinar o porcentual dessas frações sobre o total.

Os dados coletados foram submetidos à análise de variância e, quando pertinente pelo teste $\mathrm{F}$, as médias foram comparadas pelo teste de Scott-Knott. Para as leituras de clorofila realizadas ao longo do tempo, considerou-se a análise em parcelas subdivididas no tempo, utilizando-se o programa estatístico Sisvar $^{\circledR}$.

\section{Resultados e Discussão}

As maiores produtividades de grãos de milho foram observadas quando da utilização das plantas de cobertura feijão-de-porco e Crotalaria spectabilis (7.539 e $7.391 \mathrm{~kg} \mathrm{ha}^{-1}$, respectivamente) (Tabela 2). $\mathrm{O}$ incremento obtido com a utilização da cultura de cobertura feijão-de-porco (7.539 $\left.\mathrm{kg} \mathrm{ha}^{-1}\right)$ foi $24,6 \%$ superior à produtividade de grãos observada para $\mathrm{o}$ tratamento testemunha (6.052 $\mathrm{kg} \mathrm{ha}^{-1}$ no pousio). Os níveis de produtividade observados no experimento foram considerados apropriados para o nível de manejo utilizado, suplantando a média estadual de 2.174 $\mathrm{kg} \mathrm{ha}^{-1}$ (CONAB, 2016).
Observou-se que algumas espécies promoveram um decréscimo na produtividade de grãos em relação ao pousio, como a mucuna cinza, o sorgo, o capim sudão e a Crotalaria juncea. Tal fato pode estar associado a um possível efeito alelopático, uma vez que são culturas reconhecidamente possuidoras de aleloquímicos (Lemessa \& Wakjira, 2015). Ademais, há espécies que apresentam capacidade de diminuição da fertilidade do solo, pela acidificação gerada na rizosfera (Khanh et al., 2005), que, ao captarem bases na subsuperfície para a parte aérea, promovem condições de acidez em camadas mais profundas ou pela exsudação de ácidos orgânicos que promovem desequilíbrios na microfauna, tornando o ambiente menos propício para o pleno crescimento radicular (Li et al., 2014; Mukherjee \& Lal, 2015).

As culturas de cobertura milheto, Urochloa brizantha "Piatã" e "Xaraés" e mucuna preta também se destacaram na promoção das produções de grãos e de biomassa de plantas inteiras para produção de silagem. A produtividade média observada neste grupo de espécies $\left(12,8 \mathrm{Mg} \mathrm{ha}^{-1}\right)$ proporcionou um acréscimo de $22 \%$ (2,7 $\left.\mathrm{Mg} \mathrm{ha}^{-1}\right)$ no rendimento de biomassa seca do milho em relação à produtividade obtida no pousio (12,1 $\left.\mathrm{Mg} \mathrm{ha}^{-1}\right)$.

Não se verificou efeito dos tratamentos sobre a população de plantas, o índice de acamamento, o índice de espiga, a altura de planta, a altura de inserção das espigas e o particionamento de fotoassimilados (Tabela 2). A ausência de efeitos significativos das plantas de cobertura sobre esses atributos agronômicos na cultura do milho pode advir do curto período de entrada das plantas de cobertura no sistema de produção (Mukherjee \& Lal, 2015).

Na utilização de plantas de cobertura enquanto estratégia de indicação de sistemas sustentáveis de 


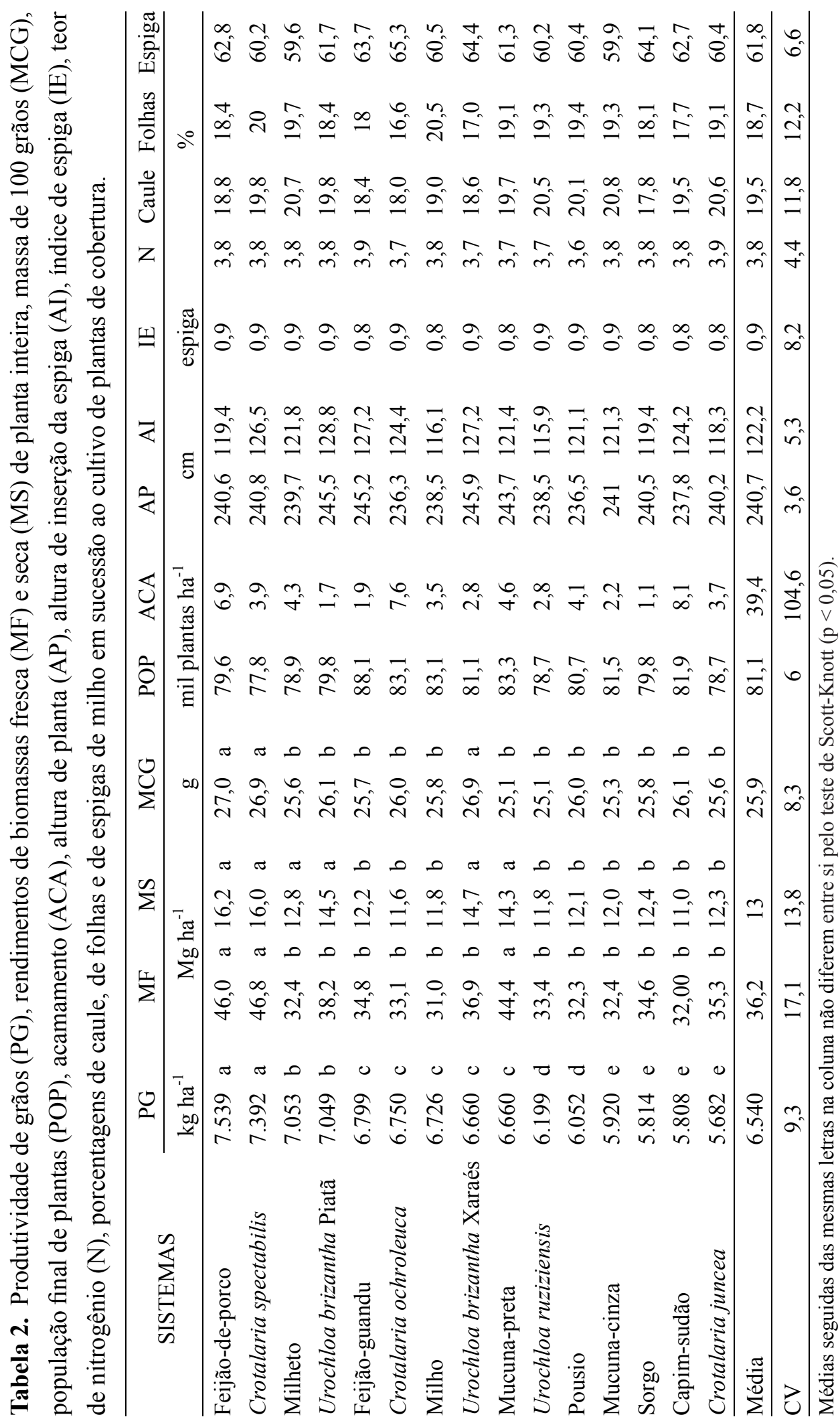


produção, se espera que os benefícios de adoção da prática sejam percebidos em médio e em longo prazos (Cerri et al., 2007). Isto se deve ao fato de que a utilização de coberturas vegetais viva e morta influencia a dinâmica biológica do solo (Franchini et al., 2007), com reflexos positivos sobre a fertilidade global, especialmente nos teores de matéria orgânica do solo após alguns anos de uso do sistema plantio direto (Maia et al., 2013).

Os diferentes sistemas de sucessão promoveram um impacto sobre a fisiologia das plantas de milho no que tange aos teores indiretos de clorofila (Tabelas 3 e 4). O teor de clorofila total indica a eficiência na absorção da radiação solar pelas folhas e, como consequência, uma maior taxa fotossintética e maiores rendimentos de grãos (Mahama et al., 2016). A avaliação indireta de clorofila é uma importante ferramenta para determinações de práticas de manejo do milho e de outras culturas, visando à obtenção de altas produtividades aliadas à utilização racional de fertilizantes nitrogenados (Schulte et al., 2007).

Avaliando-se os teores totais de clorofila, observa-se um decréscimo significativo nesses pigmentos no tratamento feijão-de-porco durante a fase de maturação de grãos (Tabela 3). A menor quantidade de clorofila total em plantas de milho semeadas em sucessão a essa planta de cobertura pode advir de uma

Tabela 3. Teores de clorofila total na cultura do milho nos estádios fenológicos pendoamento (P), florescimento feminino (F), grãos leitosos (GL), grãos pastosos (GP), grãos farináceos (GF), maturação (M) em função da espécie de cobertura utilizada.

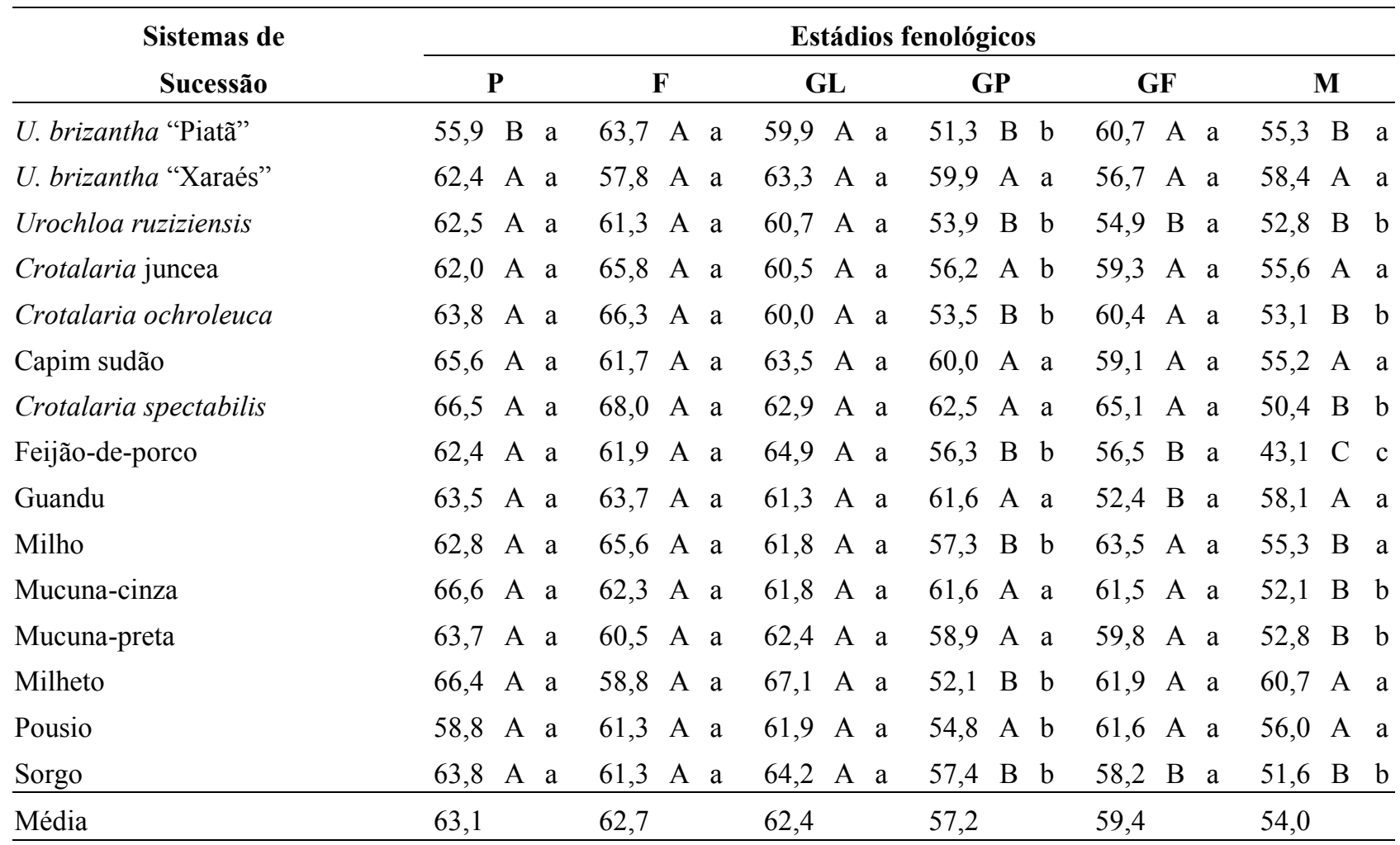

Médias seguidas de letras maiúsculas na linha e minúsculas na coluna não diferem entre si pelo teste $\operatorname{Scott}-\mathrm{Knott}(\mathrm{p}<0,05)$. 


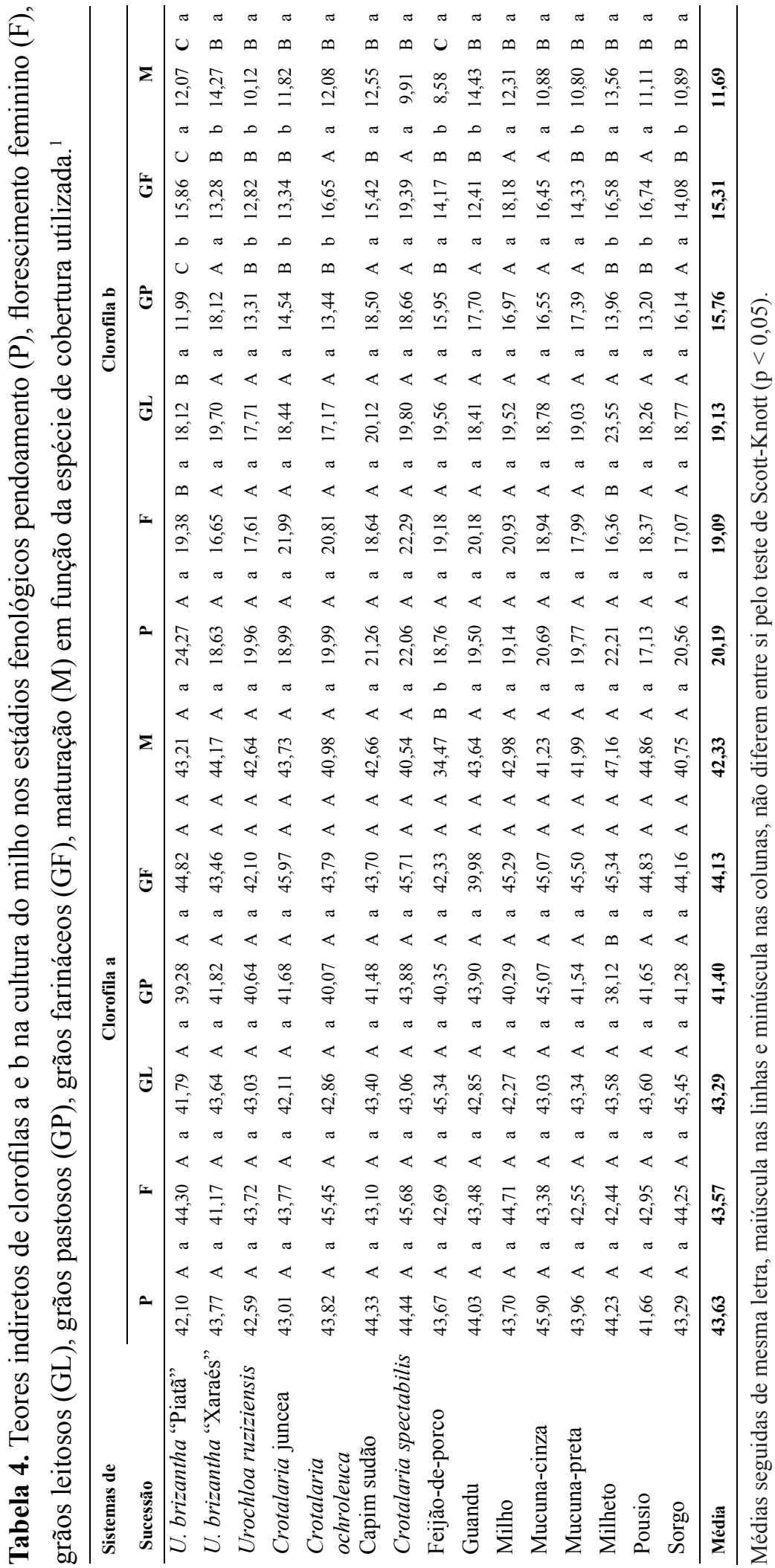


maior eficiência na redistribuição de fotoassimilados das fontes (folha) para o dreno (espigas e grãos) (Taiz \& Zeiger, 2013).

$\mathrm{Na}$ fase de pendoamento, observou-se um decréscimo nos teores foliares de clorofila total na cultura do milho cultivada sobre a palhada da Urochloa brizantha "Piatã" (Tabela 3). Tal fato pode ocorrer devido à maior imobilização do nitrogênio do solo ocorrida em função do alto aporte de carbono proporcionado pela planta de cobertura (Acosta et al., 2014), que gera momentaneamente a indisponibilização do nutriente para a planta de milho a favor dos microrganismos de solo (Franchini et al., 2007). Deve-se ressaltar que a Urochloa brizantha pode apresentar um efeito alelopático desencadeador de alterações fisiológicas nas plantas de milho que podem expressar um comportamento de resposta a estresse no qual há priorização de alocação de fotoassimilados, dentre esses, o nitrogênio, para os drenos reprodutivos (Lemessa \& Wakjira, 2015).

Ao longo do período de avaliação, os decréscimos nos teores de clorofila foram verificados em duas épocas dentro das plantas de cobertura: na maturação e no estádio de grãos pastosos (Tabela 3). Nas demais épocas, os teores de clorofila não diferiram entre si, para uma mesma planta de cobertura. Esse efeito das plantas de cobertura sobre o stay green do milho pode ser um fator preponderante para situações de estresses bióticos e correlacionado ao aumento de produtividade da lavoura (Walter et al., 2015). Segundo Streit et al. (2005), a fase inicial de degradação das clorofilas em tecidos senescentes é iniciada por fatores ambientais, tais como estresse hídrico e alterações térmicas.

Por sua vez, ao avaliar os teores de clorofila a e b, verificam-se maiores amplitude e efeito das plantas de cobertura sobre os teores de clorofila $b$ do que nos teores de clorofila a e total (Tabela 3 e Tabela 4). As menores respostas ao uso de plantas de cobertura indicadas nas clorofilas total e a remetem a uma alta resiliência desses pigmentos às condições ambientais testadas. As clorofilas desempenham papel importante na fotossíntese, sendo responsáveis pela captação de energia luminosa, destacando-se a clorofila a como o principal pigmento dos complexos coletores de luz para as reações fotoquímicas.

A clorofila a apresentou uma efetiva variação na cultura do milho semeada em sucessão ao feijãode-porco $(34,5)$, apresentando uma queda de $24,4 \%$ em relação à média dos demais tratamentos na maturação $(42,9)$. A clorofila a é utilizada durante a fase fotoquímica (o primeiro estágio do processo fotossintético), enquanto que a clorofila b é responsável pela absorção de luz e na transferência da energia radiante para os centros de reação (Taiz \& Zeiger, 2013). A concentração dessas, assim como o balanço entre as clorofilas a e b, são reflexos internos de estados de estresses ambientais atuando como aparatos fisiológicos atenuadores do estresse (Streit et al., 2005).

Ao avaliar o efeito das épocas de leitura sobre os teores da clorofila $b$, verifica-se um decréscimo significativo sobre esse pigmento ao longo do ciclo de desenvolvimento da cultura do milho em todos os tratamentos. Contudo, os maiores decréscimos foram observados durante as fases finais, entre o estádio de grãos pastosos e a maturação. Os maiores decréscimos foram observados na maturação, com perdas de até $55,1 \%$ sobre os teores iniciais observados no pendoamento para o milho precedido pela Crotalaria spectabilis, seguidos pelo feijão-de-porco $(54,3 \%)$ e pela Urochloa brizantha "Piatã" (50,3\%). O menor decréscimo foi observado no milho precedido pela Urochloa brizantha "Xaraés" (23,4\%). 


\section{Conclusões}

As plantas de cobertura feijão-de-porco e Crotalaria spectabilis apresentam-se como estratégicas para compor sistemas de produção de milho na região Sudoeste da Amazônia ao promoverem incrementos de produtividades de grãos e de silagem em relação à prática do pousio.

Observa-se um comportamento diferenciado da cultura do milho, nos estádios de maturação, quanto aos teores de clorofila, em função do uso de plantas de cobertura.

A apropriada escolha das plantas de cobertura é preponderante para o sucesso da produção de milho conduzido sob sistemas de plantio direto na região Sudoeste da Amazônia.

\section{Referências}

ACOSTA, J. A. de A.; AMADO, T. J. C.; SILVA, L. S. da; SANTI, A.; WEBER, M. A. Decomposição da fitomassa de plantas de cobertura e liberação de nitrogênio em função da quantidade de resíduos aportada ao solo sob sistema plantio direto. Ciência Rural, Santa Maria, v. 44, n. 5, p. 801-809, 2014.

DOI: $10.1590 / \mathrm{S} 0103-84782014005000002$.

ALBUQUERQUE, A. W. de; SANTOS, J. R.; FILHO, G. M.; REIS, L. S. Plantas de cobertura e adubação nitrogenada na produção de milho em sistema de plantio direto.

Revista Brasileira de Engenharia Agrícola e Ambiental, Campina Grande, v. 17, n. 7, p. 721-726, 2013.

DOI: $10.1590 / \mathrm{S} 1415-43662013000700005$.

BASCHE, A. D.; MIGUEZ, F. E.; KASPAR, T. C.; CASTELLANO, M. J. Do cover crops increase or decrease nitrous oxide emissions in agroecosystems? A meta-analysis. Journal of Soil and Water Conservation, Ankeny, v. 69, n. 6, p. 471-482, 2014.

DOI: $10.2489 /$ jswc.69.6.471.
BOER, C. A.; ASSIS, R. L.; SILVA, G. P.; BRAZ, A. J. B. P.; BARROSO, A. L. L.; CARGNELUTTI FILHO, A.; PIRES, F. R. Ciclagem de nutrientes por plantas de cobertura na entressafra em um solo de cerrado. Pesquisa Agropecuária Brasileira, Brasília, DF, v. 42, n. 9, p. 1269-1276, 2007.

DOI: $10.1590 / \mathrm{S} 0100-204 X 2007000900008$.

CARVALHO, A. M. de; COSER, T. R.; REIN, T. A.; DANTAS, R. A.; SILVA, R. R.; SOUZA, K. W. Manejo de plantas de cobertura na floração e na maturação fisiológica e seu efeito na produtividade do milho. Pesquisa Agropecuária Brasileira, Brasília, DF, v. 50, n. 7, p. 551-561, 2015.

DOI: $10.1590 / \mathrm{S} 0100-204 X 2015000700005$.

CERRI, C. E. P.; EASTER, M.; PAUSTIAN, K.; KILLIAN, K.; COLEMAN, K.; BERNOUX, M.; FALLOON, P.; POWLSON, D. S.; BATJES, N.; MILNE, E.; CERRI, C. C. Simulating SOC changes in 11 land use change chronosequences from the Brazilian Amazon with RothC and Century models. Agriculture, Ecosystems \& Environment, Berlin, v. 122, n. 1, p. 46-57, 2007.

DOI: 10.1016/j.agee.2007.01.007.

CONAB. Companhia Nacional de Abastecimento. Acompanhamento de safra brasileira: grãos: safra 2015/2016: nono levantamento. Brasília, DF, 2016. Disponível em: <http://www.conab.gov.br/OlalaCMS/ uploads/arquivos/16_06_09_16_49_15_boletim_graos junho_2016_-_final.pdf $>$. Acesso em: 20 jun. 2016.

CUNHA, A. R.; SHÖFFEL, E. R. The evapotranspiration in climate classification. In: GIACOMO, A. G. (Ed.). Evapotranspiration measurements to agricultural and environmental applications. Rijeka: InTech, 2011. p. 391411.

FRANCHINI, J. C.; CRISPINO, C. C.; SOUZA, R. A.; TORRES, E.; HUNGRIA, M. Microbiological parameters as indicators of soil quality under various tillage and crop-rotation systems in southern Brazil. Soil and Tillage Research, Amsterdam, v. 92, n. 1/2, p. 18-29, 2007.

DOI: 10.1016/j.still.2005.12.010. 
GODINHO, V. de P. C. (Ed.). Sistema de produção para a cultura do milho em Rondônia. Porto Velho: Embrapa Rondônia, 2008. 46 p. (Embrapa Rondônia. Sistema de Produção, 32).

KHANH, T. D.; CHUNG, M. I.; XUAN, T. D.; TAWATA, S. The exploitation of crop allelopathy in sustainable agricultural production. Journal of Agronomy and Crop Science, Malden, v. 191, n. 3, p. 172-184, 2005. DOI: 10.1111/j.1439-037X.2005.00172.x.

LEMESSA, F.; WAKJIRA, M. Cover crops as a means of ecological weed management in agroecosystems. Journal of Crop Science and Biotechnology, Seoul, v. 18, n. 2, p. 123-135, 2015.

DOI: $10.1007 / \mathrm{s} 12892-014-0085-2$.

LI, X.; DING, C.; HUA, K.; ZHANG, T.; ZHANG, Y.; ZHAO, L.; YANG, Y.; LIU, J.; WANG, X. Soil sickness of peanuts is attributable to modifications in soil microbes induced by peanut root exudates rather than to direct allelopathy. Soil Biology and Biochemistry, Elmsford, v. 78, n. 4, p. 149-159, 2014.

DOI: 10.1016/j.soilbio.2014.07.019.

MAHAMA, G. Y.; PRASAD, P. V. V.; ROOZEBOOM, K. L.; NIPPERT, J. B.; RICE, C. W. Response of maize to cover crops, fertilizer, nitrogen rates, and economic return. Agronomy Journal, Madison, v. 108, n. 1, p. 17-31, 2016. DOI: $10.2134 /$ agronj15.0136.

MAIA, S. M. F.; CARVALHO, J. L. N.; CERRI, C. E. P.; LAL, R.; BERNOUX, M.; GALDOS, M. V.; CERRI, C. C. Contrasting approaches for estimating soil carbon changes in Amazon and Cerrado biomes. Soil and Tillage Research, Amsterdam, v. 133, n. 4, p. 75-84, 2013.

DOI: $10.1016 /$ j.still.2013.06.002.

MOREIRA, S. G.; LUPP, R. M.; LIMA, C. G. D.; MARUCCI, R. C.; RESENDE, A. V.; BORGES, I. D. Massa seca e macronutrientes acumulados em plantas de milho cultivadas sob diferentes espécies de cobertura. Revista Brasileira de Milho e Sorgo, Sete Lagoas, v. 13, n. 2, p. 218-231, 2014.

DOI: $10.18512 / 1980-6477 /$ rbms.v13n2p218-231.
MUKHERJEE, A.; LAL, R. Short-term effects of cover cropping on the quality of a Typic Argiaquolls in Central Ohio. Catena, Amsterdam, v. 131, n. 2, p. 125-129, 2015. DOI: 10.1016/j.catena.2015.02.025.

PILON, C.; SORATTO, R. P.; BROETTO, F.; FERNANDES, A. M. Foliar or soil application of silicon alleviate water-deficit stress of potato plants. Agronomy Journal, Madison, v. 106, n. 6, p. 2325-2334, 2014.

DOI: $10.2134 /$ agronj14.0176.

ROSA, D. M.; NÓBREGA, L. H. P.; LIMA, G. P.; MAULI, M. M. Desempenho da cultura do milho implantada sobre resíduos culturais de leguminosas de verão em sistema plantio direto. Semina: Ciências Agrárias, Londrina, v. 32, n. 4, p. 1287-1296, 2011.

DOI: $10.5433 / 1679-0359.2011 v 32 n 4 p 1287$.

SCHLINDWEIN, J. A.; MARCOLAN, A. L.; PASSOS, A. M. A.; MILITÃO, J. S. L. T.; FIORELLI-PEREIRA, E. C.; PEREIRA, A. P. M.; TONINI, J. Atualizações em calagem de solos em Rondônia. In: WADT, P. G. S.; MARCOLAN, A. L.; MATOSO, S. C. G.; PEREIRA, M. G. (Org.). Manejo dos solos e a sustentabilidade da produção agrícola na Amazônia Ocidental. Porto Velho: Núcleo Regional Amazônia Ocidental: SBCS, 2014. v. 1, p. $267-287$.

SCHULTE AUF'M ERLEY, G.; WIJAYA, K. A.; ULAS, A.; BECKER, H.; WIESLERD, F.; HORST, W. J. Leaf senescence and $\mathrm{N}$ uptake parameters as selection traits for nitrogen efficiency of oilseed rape cultivars. Physiologia Plantarum, Hoboken, v. 130, n. 4, p. 519-531, 2007.

DOI: 10.1111/j.1399-3054.2007.00921.x.

SOUZA SOBRINHO, F. de; OLIVEIRA, J. S. e; LOPES, F. C. F.; AUAD, M. V. Tamanho de parcela e necessidade de bordadura em avaliações de cultivares de milho para silagem. Revista Brasileira de Milho e Sorgo, Sete Lagoas, v. 3, n. 1, p. 45-51, 2004.

DOI: $10.18512 / 1980-6477 /$ rbms.v3n1p45-51.

STREIT, N. M.; CANTERLE, L. P.; CANTO, M. W. do; HECKTHEUER, L. H. H. The chlorophylls. Ciência Ru- 
ral, Santa Maria, v. 35, n. 3, p. 748-755, 2005. DOI: $10.1590 / \mathrm{S} 0103-84782005000300043$.

WALTER, L. C.; ROSA, H. T.; STRECK, N. A. Mecanismos de aclimatação das plantas à elevada concentração de $\mathrm{CO}_{2}$ Ciência Rural, Santa Maria, v. 45, n. 9, p. 1564-1571, 2015. DOI: $10.1590 / 0103-8478 \mathrm{cr} 20140527$.

TAIZ, L.; ZEIGER, E. Fisiologia vegetal. 5. ed. Porto Alegre: Artmed, 2013. $954 \mathrm{p}$
ZIECH, A. R. D.; CONCEIÇÃO, P. C.; LUCHESE, A. V.; BALIN, N. M.; CANDIOTTO, G.; GARMUS, T. G. Proteção do solo por plantas de cobertura de ciclo hibernal na região Sul do Brasil. Pesquisa Agropecuária Brasileira, Brasília, DF, v. 50, n. 5, p. 374-382, 2015. DOI: 10.1590/S0100-204X2015000500004. 